\title{
Gender differences in outcomes after surgical ablation of atrial fibrillation
}

\author{
Sonia V. Shah, BS, ${ }^{\mathrm{a}}$ Jane Kruse, BSN, ${ }^{\mathrm{d}}$ Adin-Cristian Andrei, PhD, ${ }^{\mathrm{d}} \mathrm{Zhi}$ Li, MS, ${ }^{\mathrm{d}}$ S. Chris Malaisrie, MD, \\ Bradley P. Knight, MD, ${ }^{\mathrm{c}}$ Rod S. Passman, MD, ${ }^{\mathrm{c}}$ and Patrick M. McCarthy, MD ${ }^{\mathrm{b}}$
}

\section{ABSTRACT}

Background: Gender disparities have been established in patients who have atrial fibrillation (AF), and in their outcomes after medical treatment for AF. This study evaluated differences in outcome by gender in patients who underwent surgical treatment for AF.

Methods: From April 2004 to December 2012, a total of 936 patients had surgical treatment for AF. Outcomes were analyzed by gender using propensity scorematching methods.

Results: Of the 936 subjects, $571(61 \%)$ were men; women were older (aged $68.6 \pm 11.3$ vs $66.9 \pm 11.9$ years; $P=.033)$, had more heart failure $(44 \%$ vs $37 \% ; P=.024)$, more mitral valve surgery $(72 \%$ vs $50 \% ; P<.001)$ and more tricuspid valve surgery $(41 \%$ vs $18 \% ; P<.001)$. Men underwent more coronary artery bypass surgery $(37 \%$ vs $19 \% ; P<.001)$ and aortic valve surgery $(38 \%$ vs $31 \% ; P=.029)$. Women had higher late stroke rate per 10 person-years $(0.15 \mathrm{vs}$ $0.07 ; P=.035)$, fewer catheter ablations $(6.0 \%$ vs $9.8 \% ; P=.017)$, and a trend toward fewer cardioversions for recurrent AF $(15.7 \%$ vs $19.2 \% ; P=.20)$. After propensity-score matching, late stroke rates per 10 person-years trended higher in women $(0.12$ vs $0.04 ; P=.13)$. No significant gender differences were found in overall survival (5-year survival: $78.8 \%$ in men, and $81.0 \%$ in women; $P=.40$ ) or freedom from AF without antiarrhythmic drugs at last follow-up $(71.8 \%$ in men vs $73.6 \%$ in women, $P=.59$ ).

Conclusions: Women sought surgery treatment at older ages and with more heart failure. No gender-based differences were found in stroke, overall survival, or procedure success, after propensity-score matching. (J Thorac Cardiovasc Surg $2016 ; 151: 391-8)$

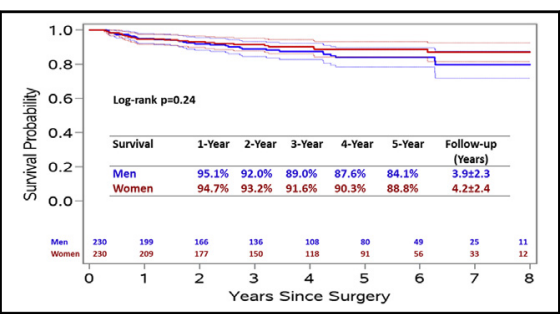

Kaplan-Meier estimate of patients alive at 90 days postsurgery in propensity-matched groups.

Central Message

Gender-based differences are present in patients undergoing surgical ablation of $\mathrm{AF}$ Matched long-term survival and outcomes were similar for women and men.

\section{Perspective}

Despite older age and higher comorbidities before surgery, women, compared with men, have similarly favorable long-term survival, procedure outcome, and late freedom from AF off AADs. Late interventions with cardioversion and catheter ablation were similar after propensity-score matching. These findings support concomitant AF surgery in qualifying patients, regardless of gender.

See Editorial Commentary page 399

See Editorial page 298.
Atrial fibrillation (AF) is a common diagnosis in patients presenting for cardiac surgery, yet little is known about the outcome of AF surgery for women compared with

\footnotetext{
From the Divisions of ${ }^{\mathrm{a}}$ Medicine, ${ }^{\mathrm{b}} \mathrm{Cardiac}$ Surgery, and ${ }^{\mathrm{c}}$ Cardiology, Northwestern University; and ${ }^{\mathrm{d}}$ Bluhm Cardiovascular Institute, Northwestern Medicine, Chicago, Ill.

Financial support was provided in part by the American Association for Thoracic Surgery Summer Intern Scholarship.

Received for publication May 6, 2015; revisions received Aug 27, 2015; accepted for publication Sept 7, 2015; available ahead of print Oct 24, 2015.

Address for reprints: Patrick M. McCarthy, MD, Division of Cardiac Surgery,

Northwestern University, 201 E Huron St, Ste 11-140, Chicago, IL 60611-2908

(E-mail: lhuerta@nm.org).

$0022-5223 / \$ 36.00$

Copyright (C) 2016 by The American Association for Thoracic Surgery

http://dx.doi.org/10.1016/j.jtcvs.2015.09.062
}

men. Overall survival for patients with AF has been shown to be lower than it is for patients who are in sinus rhythm. In the medical literature, gender-related differences in AF presentation, medical treatment, and outcome have shown that women have a longer history and duration of $\mathrm{AF}$ episodes, are referred for treatment later, and are more likely to have valvular heart disease. ${ }^{2,3}$

Scanning this QR code will take you to supplemental figure and table for this article.

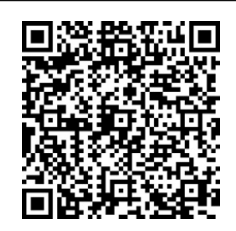




\section{Abbreviations and Acronyms \\ $\mathrm{AAD}=$ antiarrhythmic drug \\ AF $\quad=$ atrial fibrillation \\ CHADS2 = cardiac failure, hypertension, \\ age, diabetes, stroke (double) \\ CHA2DS2-VASc $=$ cardiac failure, hypertension, age $>75$ years (double), \\ diabetes, stroke (double), \\ vascular disease, age 65- \\ 74 years, and sex (female) \\ STS}

Women experience more side effects from antiarrhythmic drugs (AADs), have a greater risk of thromboembolic events, and experience greater impairment in quality of life upon diagnosis of $\mathrm{AF}^{2,4-6}$ Fairly uniform findings indicate that women with $\mathrm{AF}$ have a higher risk for stroke, although the reason is unclear. ${ }^{7,8}$ In fact, the CHADS2 (cardiac failure, hypertension, age, diabetes, stroke [double]) score was refined to account for female gender as a risk factor for stroke, resulting in the CHA2DS2-VASc (cardiac failure, hypertension, age $>75$ years [double], diabetes, stroke [double], vascular disease, age 65-74 years, and sex [female]) schema.

Studies in gender differences after catheter ablation have produced mixed results, with some suggesting similar ourcomes, ${ }^{9,10}$ and others reporting more complications and AF recurrence in women. ${ }^{6}$ However, women are consistently less likely to achieve freedom from $\mathrm{AF}$ and are less likely to undergo repeat catheter ablation. ${ }^{11-13}$

According to the national Society of Thoracic Surgeons (STS) database, $11 \%$ of patients undergoing heart surgery have a history of AF. ${ }^{14}$ Surgical treatment of AF in patients undergoing cardiac surgery is safe, effective, and does not increase perioperative morbidity and mortality when added to cardiac surgery procedures. ${ }^{15-20}$ Treatment of AF at the time of surgery is recommended in a joint consensus statement for the Heart Rhythm Society and the STS. ${ }^{21}$ However, only one study was found on AF and gender in the cardiac surgery literature; the study indicated numerous differences at baseline. ${ }^{22}$

Therefore, the rationale for this study was to assess possible differences in outcome, especially stroke, in the original groups and after propensity-score matching. Theoretically, if differences were identified, as in the cardiology literature, then a different approach to the AF surgery or the left atrial appendage might be warranted.

\section{METHODS \\ Patients}

Data for this project were obtained from the Cardiovascular Research Database of the Bluhm Cardiovascular Institute at Northwestern Memorial Hospital. This database was approved by the Northwestern University Institutional Review Board (project \# STU00012288). Those within the database who refused participation in the project were not included in the analysis.

From April 2004 to December 2012, cardiac surgery was performed on 5353 patients (excluding those with transcatheter aortic valve implants, ventricular assist devices, trauma, or transplant), and 1248 had preoperative AF. Of those, $936(75 \%)$ were surgically treated for AF. Survival data were acquired from various sources, including the following: patient follow-up, cardiovascular research database; registry surveys; and online death indexes such as the Social Security Death Index and genealogy resources that provide copies of Social Security death information supplied directly by family members. From these sources, follow-up information was available on $100 \%$ of the cohort. The STS database definitions were used for 30-day mortality.

\section{Atrial Fibrillation Monitoring Protocol}

The postoperative AF monitoring protocol was standardized in collaboration with electrophysiologists. Patients were discharged with AADs and anticoagulant medication, if these were not contraindicated. For any patients with postoperative persistent atrial flutter or AF, cardioversion at 6 to 8 weeks after surgery was recommended. At 3 months, an office electrocardiogram to confirm sinus rhythm was performed before placement of mobile cardiac outpatient telemetry (CardioNet, Conshohocken, Pa; or ACT Ambulatory Cardiac Telemetry, LifeWatch Services, Inc, Rosemont, Ill). Alternatively, recommendations were made for a 30-day event monitor or a Holter monitor at the cardiologist's discretion.

If a patient had AF or atrial flutter by electrocardiogram, and the clinicians and patient chose not to attempt further efforts to return to sinus rhythm, then that patient was considered to be a failure of treatment and no further monitoring was obtained. Patients with dual-chamber implanted defibrillators or pacemakers had mode-switch parameters activated to track atrial arrhythmias. In addition, monitor results were obtained from cardiac rehabilitation sessions. After 3 months, AADs were withdrawn at the discretion of the cardiologist if sinus rhythm was documented, and the patient had no symptoms that suggested AF. Patients with persistent atrial flutter, AF, or atrial tachycardia were offered referral to electrophysiology for catheter ablation.

Monitoring with mobile cardiac outpatient telemetry or 30-day event monitors was performed again at 6 months, and anticoagulation was discontinued for the patients who maintained sinus rhythm without AADs, at the discretion of the cardiologist and guided by the CHADS2 score, or more recently, the CHA2DS2-VASc score. ${ }^{19}$ Summaries of these risk-stratification tools were provided to the referring cardiologists. Telephone follow-up was performed by the AF nurses within the first month, and again at 3,6, and 12 months.

Database surveys were sent at 3, 6, and 12 months, and annually thereafter. Copies of medical records were obtained for any procedures or hospitalizations, to verify self-reported events such as late stroke or recurrent arrhythmia; follow-up was available on 872 patients $(93 \%)$ at a mean of $4 \pm 2.62$ years. Although rhythm monitoring using a Holter monitor or more-extensive devices was advised, the study was not a prospective trial with prespecified study visits, so monitor choice at follow-up was largely determined by the referring cardiologists. Episodes of AF, atrial flutter, or atrial tachycardia of $>30$ seconds, after the 90-day blanking period, were defined as treatment failure, per the Heart Rhythm Society-STS consensus statement. ${ }^{19}$ The STS database definitions were used for all variables. 
TABLE 1. Preoperative and intraoperative characteristics of patients, by gender

\begin{tabular}{|c|c|c|c|}
\hline Variable & $\begin{array}{c}\text { Men } \\
(\mathrm{n}=\mathbf{5 7 1})\end{array}$ & $\begin{array}{c}\text { Women } \\
(\mathbf{n}=\mathbf{3 6 5})\end{array}$ & $\begin{array}{c}P \\
\text { value }\end{array}$ \\
\hline Age (y) & $66.9 \pm 11.9$ & $68.6 \pm 11.3$ & .033 \\
\hline Body mass index $\left(\mathrm{kg} / \mathrm{m}^{2}\right)$ & $28.0 \pm 5.1$ & $27.6 \pm 6.9$ & .27 \\
\hline Left-ventricular ejection fraction & $55(45,60)$ & $58(50,66)$ & $<.001$ \\
\hline Left atrial size & $4.5(3.9,5.1)$ & $4.5(4.0,5.0)$ & .60 \\
\hline Diabetes & $95(17)$ & $63(17)$ & .80 \\
\hline Dyslipidemia & $359(63)$ & $181(50)$ & $<.001$ \\
\hline Hypertension & $392(69)$ & $225(62)$ & .027 \\
\hline Chronic lung disease & 75 (13) & $65(18)$ & .05 \\
\hline Previous stroke & $47(8)$ & $33(9)$ & .67 \\
\hline Previous myocardial infarction & $78(14)$ & $31(8)$ & .016 \\
\hline Congestive heart failure & $211(37)$ & $162(44)$ & .024 \\
\hline Coronary artery disease & $264(46)$ & $104(28)$ & $<.001$ \\
\hline Statins & $242(42)$ & $115(32)$ & $<.001$ \\
\hline Digitalis & $92(16)$ & $92(25)$ & .003 \\
\hline Antiarrhythmics & $110(19)$ & $95(26)$ & .022 \\
\hline Perfusion time (min) & $124(99,156)$ & $117(90,142)$ & $<.001$ \\
\hline Crossclamp time (min) & $94(74,121)$ & $83(65,105)$ & $<.001$ \\
\hline Atrial fibrillation duration (y) & $3.0(0.5,8.0)$ & $3.0(0.5,7.5)$ & .74 \\
\hline Coronary artery bypass grafting & $214(37)$ & $70(19)$ & $<.001$ \\
\hline Aortic valve surgery & $215(38)$ & $112(31)$ & .029 \\
\hline Tricuspid valve surgery & $104(18)$ & $151(41)$ & $<.001$ \\
\hline Mitral valve surgery & $283(50)$ & $263(72)$ & $<.001$ \\
\hline Atrial fibrillation type & & & .53 \\
\hline Paroxysmal & $291(51)$ & $197(54)$ & \\
\hline Persistent & $80(14)$ & $43(12)$ & \\
\hline Long-standing persistent & $200(35)$ & $125(34)$ & \\
\hline Left atrial appendage closure & $488(85)$ & $327(90)$ & .07 \\
\hline Atrial fibrillation ablation type & & & $<.001$ \\
\hline Biatrial & $140(25)$ & $138(38)$ & \\
\hline Classic & $63(11)$ & $43(12)$ & \\
\hline Left only & $195(34)$ & $134(37)$ & \\
\hline Pulmonary vein isolation & $173(30)$ & $50(13)$ & \\
\hline
\end{tabular}

Values are mean $\pm \mathrm{SD} ; \mathrm{n}(\%)$; or median (first quartile, third quartile).

\section{Surgical Procedures}

Isolated AF surgery occurred in $95(10 \%)$ patients; in the remainder of the cohort, $327(35 \%)$ underwent aortic valve surgery, $546(58 \%)$ mitral valve surgery, $255(27 \%)$ tricuspid valve surgery, and 284 $(30 \%)$ coronary artery bypass grafting (Table 1), either separately or in various combinations. The decision to treat $\mathrm{AF}$, and the choice of the lesion set, were made at the surgeon's discretion and performed when the benefit-to-risk ratio for ablation surgery was deemed sufficiently high, in accordance with the Heart Rhythm Society-STS recommendations. ${ }^{19}$ No gender-based differences were found in type of $\mathrm{AF}$, but a difference in the $\mathrm{AF}$ surgical procedure, based on gender, did occur (Table 1).

\section{Statistical Analysis}

Continuously distributed variables were summarized using means with SDs, or medians with interquartile ranges, and gender comparisons were based on 2-sample $t$ tests, or Wilcoxon rank sum tests. For binary or discrete variables, proportions were calculated and compared using $\chi^{2}$ analysis or the Fisher exact test. Type and frequency of AF monitoring
TABLE 2. Summary of late events for patients, by gender

\begin{tabular}{|c|c|c|c|c|}
\hline Groups & $\begin{array}{l}\text { Men: } \\
\text { Women }\end{array}$ & Men & Women & $\begin{array}{c}P \\
\text { Value }\end{array}$ \\
\hline \multicolumn{5}{|c|}{ Original groups } \\
\hline $\begin{array}{l}\text { Freedom from } \mathrm{AF} \\
\text { at } 1 \text { y (day } 274-455 \\
\text { postsurgery) }\end{array}$ & - & $205 / 294(69.7)$ & $135 / 183(73.8)$ & .34 \\
\hline $\begin{array}{l}\text { Freedom from AF } \\
\text { at last follow-up } \\
\text { off AADs }\end{array}$ & - & $333 / 464(71.8)$ & $206 / 280(73.6)$ & .59 \\
\hline \multicolumn{5}{|l|}{ Lesion type } \\
\hline Biatrial & 140: 138 & $74 / 108(68.5)$ & 75/109 (68.8) & .96 \\
\hline $\begin{array}{c}\text { Classic "cut } \\
\text { and sew" }\end{array}$ & $63: 43$ & $45 / 55(81.8)$ & 29/35 (82.9) & .90 \\
\hline Left atrial only & 195: 134 & $116 / 163(71.2)$ & 74/98 (75.50) & .45 \\
\hline $\begin{array}{l}\text { Pulmonary vein } \\
\text { isolation }\end{array}$ & 173: 50 & $98 / 138(71.0)$ & 29/38 (73.7) & .75 \\
\hline \multicolumn{5}{|c|}{ Monitoring used in follow-up } \\
\hline Electrocardiogram & - & $469 / 499(94.0)$ & 285/317 (89.9) & .032 \\
\hline $\begin{array}{l}\text { Event monitor or } \\
\text { outpatient } \\
\text { telemetry }\end{array}$ & - & $201 / 499(39.3)$ & $127 / 317(40.1)$ & .95 \\
\hline $\begin{array}{l}\text { Cardiac rehabilitation } \\
\text { reports }\end{array}$ & - & $62 / 499(12.4)$ & 43/317 (13.6) & .64 \\
\hline Implanted devices & - & $121 / 499(24.3)$ & $92 / 317(29.0)$ & .13 \\
\hline Holter monitoring & - & $148 / 499(29.7)$ & $100 / 317(31.6)$ & .57 \\
\hline Freedom from ablation & - & $460 / 516(89.2)$ & 299/318 (94.0) & .017 \\
\hline $\begin{array}{l}\text { Freedom from } \\
\text { cardioversion }\end{array}$ & - & $417 / 516(80.8)$ & $268 / 318(84.3)$ & .20 \\
\hline $\begin{array}{l}\text { Stroke rate per } 10 \\
\text { person-years }\end{array}$ & - & 0.07 & 0.15 & .035 \\
\hline
\end{tabular}

\begin{tabular}{|c|c|c|c|c|}
\hline \multicolumn{5}{|c|}{ Propensity score-matched groups } \\
\hline $\begin{array}{l}\text { Freedom from AF } \\
\text { at } 1 \text { y (day } \\
274-455 \\
\text { postsurgery) }\end{array}$ & - & $88 / 128(68.8)$ & $91 / 125(72.4)$ & .48 \\
\hline $\begin{array}{c}\text { Freedom from AF } \\
\text { at last follow- } \\
\text { up off AADs }\end{array}$ & - & $142 / 199(71.4)$ & 147/197 (74.6) & .46 \\
\hline \multicolumn{5}{|l|}{ Lesion type } \\
\hline Biatrial & 79: 80 & $39 / 60(65.0)$ & $44 / 64(68.8)$ & .66 \\
\hline $\begin{array}{l}\text { Classic "cut } \\
\text { and sew" }\end{array}$ & 27: 39 & $18 / 24(75.0)$ & $27 / 35(77.1)$ & .62 \\
\hline Left atrial only & 98: 87 & $59 / 79(74.7)$ & $51 / 67(76.1)$ & .84 \\
\hline $\begin{array}{l}\text { Pulmonary vein } \\
\text { isolation }\end{array}$ & 47: 45 & $26 / 36(72.2)$ & $27 / 35(77.1)$ & .63 \\
\hline $\begin{array}{l}\text { Freedom from } \\
\text { ablation }\end{array}$ & - & $195 / 220(88.6)$ & $206 / 223(92.4)$ & .18 \\
\hline $\begin{array}{l}\text { Freedom from } \\
\text { cardioversion }\end{array}$ & - & $177 / 220(80.5)$ & $188 / 223(84.3)$ & .29 \\
\hline $\begin{array}{l}\text { Stroke rate per } 10 \\
\text { person-years }\end{array}$ & - & 0.04 & 0.12 & .13 \\
\hline
\end{tabular}
person-years

Values are $\mathrm{n} /$ total in category (\%), unless otherwise indicated. Original groups: men, $\mathrm{n}=571$; women, $\mathrm{n}=365$. Score-matched groups: men, $\mathrm{n}=251$; women, $\mathrm{n}=251$. Freedom measured by 90 -day blanking period, unless otherwise indicated. $A F$, Atrial fibrillation; $A A D$, antiarrhythmia drug. 
Original Groups

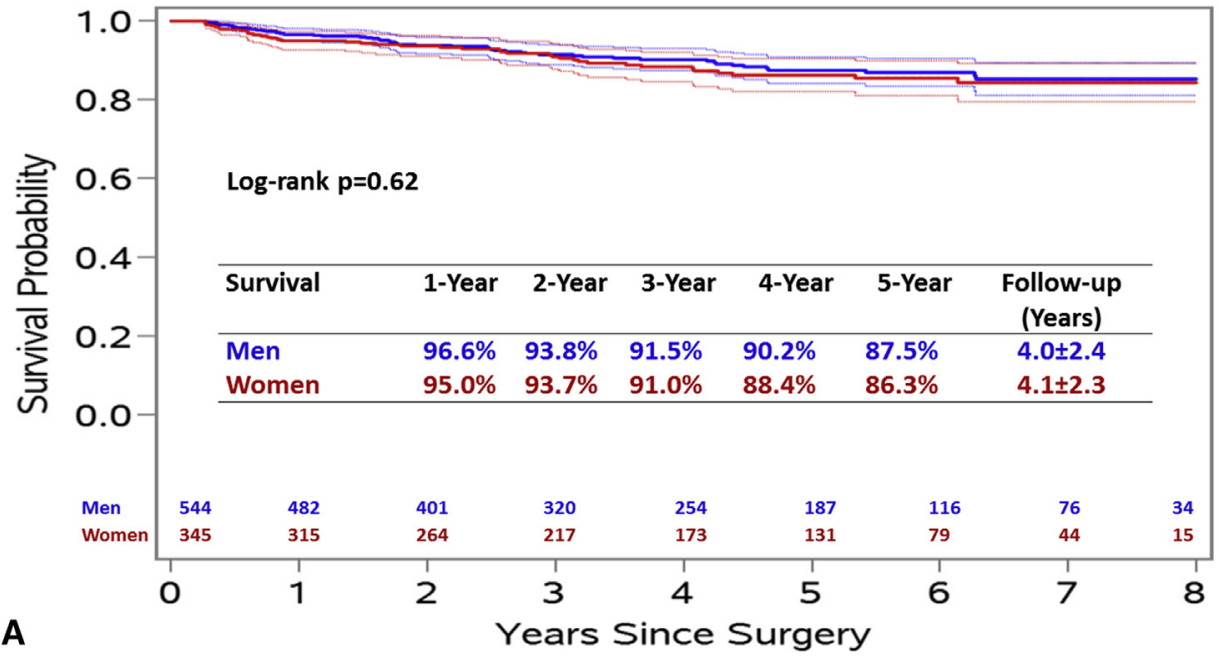

Propensity Score-Matched Groups

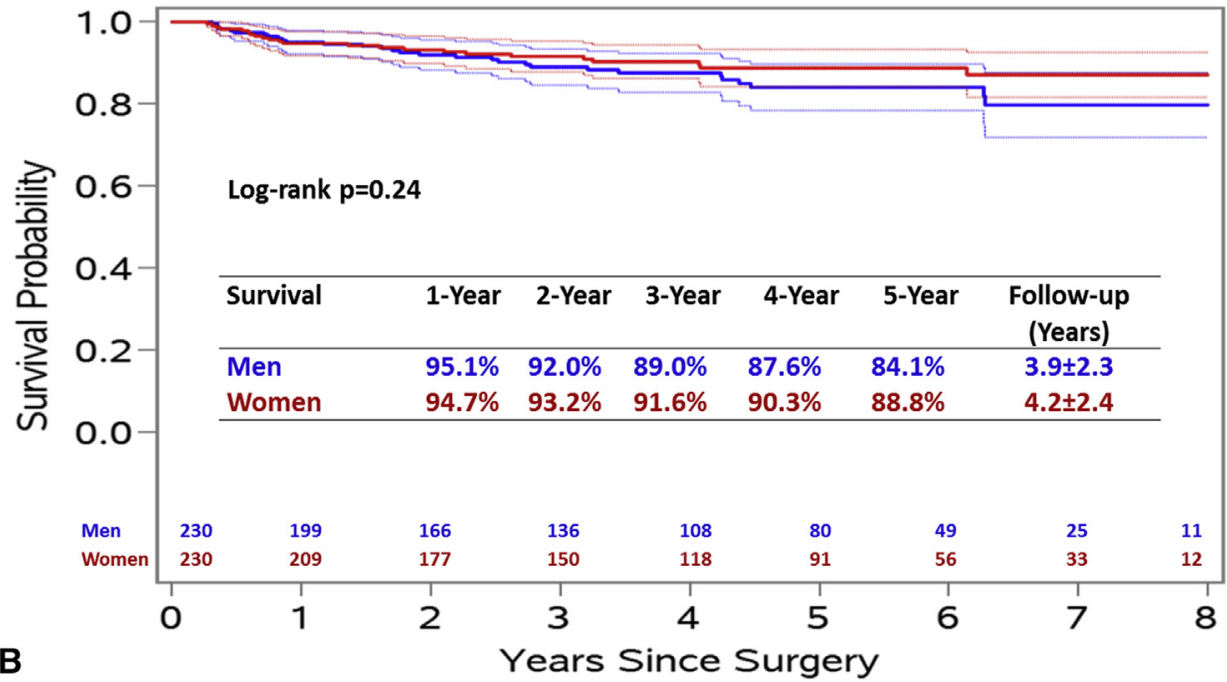

FIGURE 1. Kaplan-Meier survival estimates with pointwise $95 \%$ confidence intervals, in the (A) original groups and (B) propensity score-matched groups.

were compared, as a means to document that no gender bias occurred in relation to follow-up intensity (Table 2).

To account for baseline differences between women and men, one-toone propensity score-matching methods were used, with a caliper of size 0.02 logit propensity score SD units. For each baseline covariate included in the propensity-score model, balance between genders was assessed using standardized differences. Propensity score-matching factors included the following: age; body mass index; aortic, mitral, or tricuspid valve surgery; coronary artery disease; family history of coronary artery disease; diabetes; hypercholesterolemia; hypertension; prior myocardial infarction; prior coronary artery bypass grafting: prior valve surgery; prior cardiovascular intervention; prior congestive heart failure; New York Heart Association functional class III/IV; repeat sternotomy; elective status; and preoperative medication (lipid-lowering drugs; AADs). Long-term overall survival, in both the original and matched groups, was summarized using KaplanMeier curves; gender comparisons were based on the log-rank test.

Stroke rates per 10 person-years were calculated and compared by gender, using exact methods for incidence-rate data, ${ }^{23}$ for both unmatched and propensity score-matched analyses. In addition, we estimated the probability of stroke using the Aalen-Johansen estimator in a semicompeting risks analysis based on a 3-state Markov model ${ }^{24}$; gender comparisons at various time points were based on $\mathrm{Z}$-scores derived from the respective pointwise estimates and their SDs.

Throughout the analyses, a 2-sided 5\% statistical significance level was used, without multiplicity adjustments. All analyses were performed using SAS 9.3 (SAS Institute Inc, Cary, NC). 


\section{RESULTS}

In the original groups, women differed from men in that they were older, had greater use of digitalis, higher prevalence of chronic lung disease, and were more likely to be in New York Heart Association functional class III or IV. Men had greater body surface area, and a higher prevalence of hypertension, dyslipidemia, previous myocardial infarction, and coronary artery disease. Women underwent more mitral valve surgery, as well as tricuspid valve surgery, whereas men were more likely to undergo concomitant coronary artery bypass grafting, aneurysm repair, and aortic valve surgery (Table 1).

As a result of these differences, lesion type (biatrial, classic, left only, or pulmonary vein isolation) differed between genders; men underwent pulmonary vein isolation more frequently, whereas women had more biatrial ablation. The CHADS2 score was similar between genders $(P=.59)$, but in follow-up, women had a significantly higher stroke rate per 10 person-years $(0.15$ vs 0.07 ; $P=.035)$. In unmatched data, the stroke rate was higher in women when the left atrial appendage was treated $(5.3 \%$ vs $2.8 \% ; P=.038)$, but overall no difference in stroke rate was found for men compared with women ( $3 \%$ vs $5.3 \%$, respectively; $P=.89$ ).

However, given that the stroke rate might not be constant over time, we estimated the probability, by gender, of stroke during the first 8 years of follow-up, and found no significant difference. Women were significantly less likely to undergo treatment of recurrent $\mathrm{AF}$ with catheter ablation $(P=.025)$ (Appendix E1, Table E1). Overall survival (Figure 1, A) did not differ significantly by gender $(P=.50)$, with a 5 -year survival of $82.2 \%$ in men and $80.6 \%$ in women.

Propensity-score matching resulted in reduced standardized differences in baseline covariates (Figure 2). Women and men had similar median length of hospital stay (8 vs 7 days, respectively; $P=.12$; Table 3 ). Stroke rates per 10 person-years trended higher among women (0.12 vs 0.04; $P=.13$ ), regardless of whether the left atrial appendage was closed; the same trends were observed in probabilities of stroke (Figure 3). No gender differences were found in late cardioversion $(P=.29)$ or catheter ablation $(P=.18)$. Compared with men, women achieved similar rates of freedom from AF without AADs at last follow-up (74.6\% women vs $71.6 \%$ men; $P=.46)$. No significant differences were found in overall survival (Figure $1, B ; P=.40$ ), with a 5 -year survival of $78.8 \%$ in men versus $81.0 \%$ in women.

\section{DISCUSSION}

Despite differences in baseline characteristics between women and men who undergo surgical ablation for AF, short- and long-term outcomes were similar in propensity

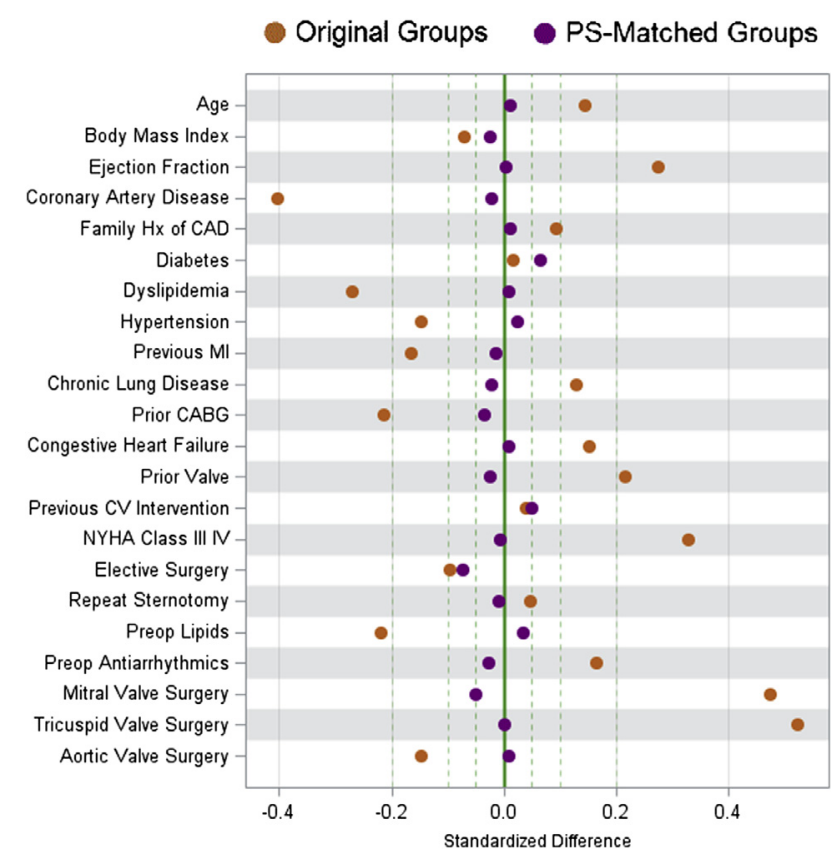

FIGURE 2. Standardized differences in baseline covariates in the PS model, before and after PS-matching. $P S$, Propensity score; $H x$, history; $C A D$, coronary artery disease; $M I$, myocardial infarction; $C A B G$, coronary artery bypass grafting; $C V$, cardiovascular; NYHA, New York Heart Association; preop, preoperative.

score-matched analyses. Specifically, women and men had similar survival rates, freedom from $\mathrm{AF}$, and treatment with either cardioversion or catheter ablation in instances of AF recurrence.

A recent study by Henry and colleagues ${ }^{22}$ reported differences in baseline characteristics and outcomes; our study differs from that one in several respects. In our cohort, men needed aortic valve replacement more frequently than did women, resulting in differences in lesion set by gender. Men underwent pulmonary vein isolation more frequently, whereas women had more mitral and tricuspid valve

TABLE 3. Propensity score-matched analyses: postoperative characteristics of patients, by gender

\begin{tabular}{lccc}
\hline \multicolumn{1}{c}{ Variable } & $\begin{array}{c}\text { Men } \\
(\mathbf{n}=\mathbf{2 5 1})\end{array}$ & $\begin{array}{c}\text { Women } \\
(\mathbf{n}=\mathbf{2 5 1})\end{array}$ & $\boldsymbol{P}$ value \\
\hline Total length of stay (d) & $7(5,12)$ & $8(6,12)$ & .12 \\
Postoperative length of stay (d) & $7(5,10)$ & $7(6,10)$ & .11 \\
Postoperative stroke $>24 \mathrm{~h}$ & $6(2)$ & $4(2)$ & .52 \\
Transient ischemic attack & $0(0)$ & $4(2)$ & .045 \\
Prolonged ventilation $>24 \mathrm{~h}$ & $28(11)$ & $27(11)$ & .89 \\
Anticoagulant event & $0(0)$ & $4(2)$ & .045 \\
Discharged on antiarrhythmia drugs & $166(66)$ & $168(67)$ & .98 \\
Discharged on statins & $197(80)$ & $182(74)$ & .11 \\
Discharged on warfarin & $224(89)$ & $222(88)$ & .95 \\
Discharged to home & $184(73)$ & $168(67)$ & .28 \\
\hline
\end{tabular}

Values are $\mathrm{n}(\%)$; or median (first quartile, third quartile), unless otherwise indicated. 


\section{Original Groups}

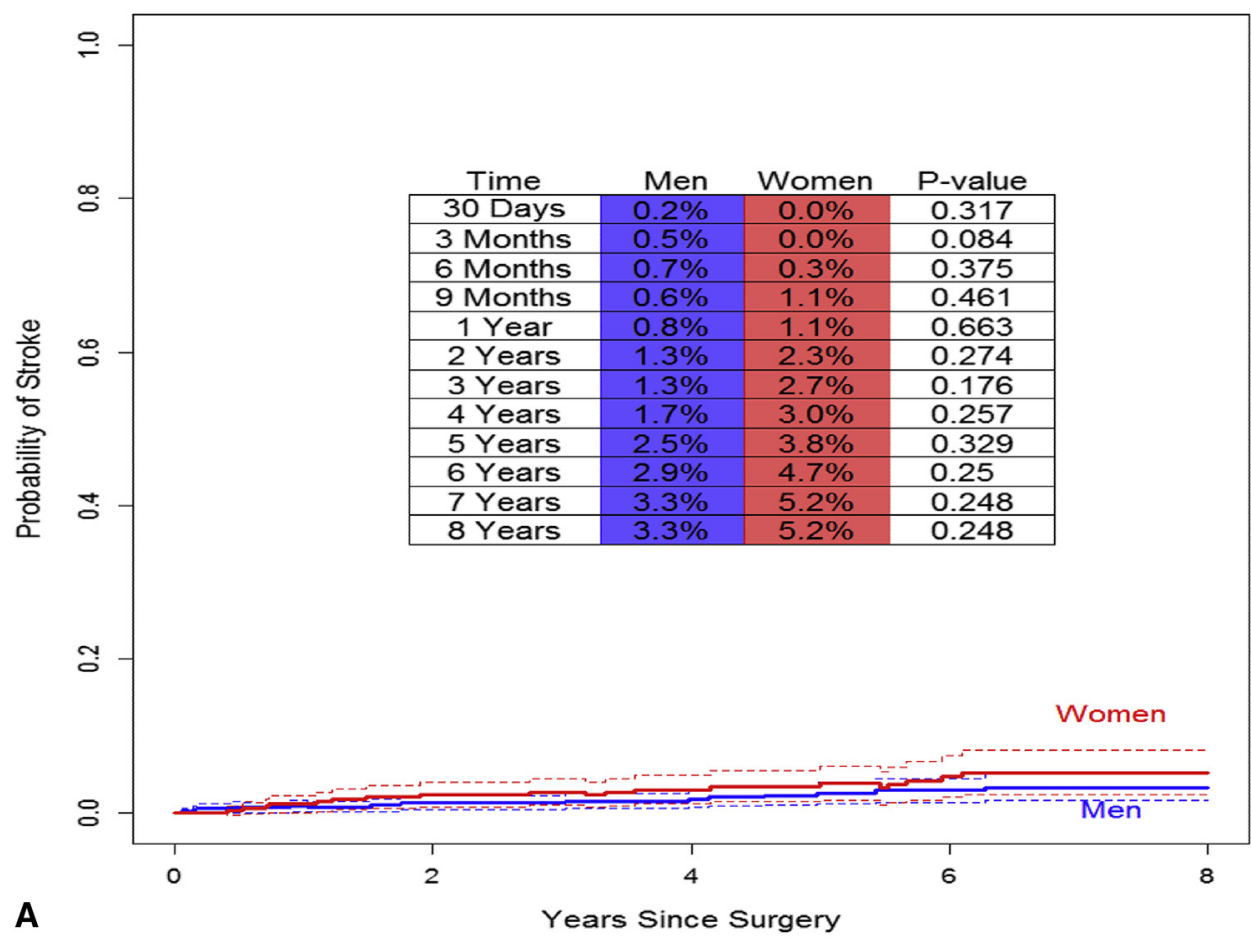

\section{Propensity Score-Matched Groups}

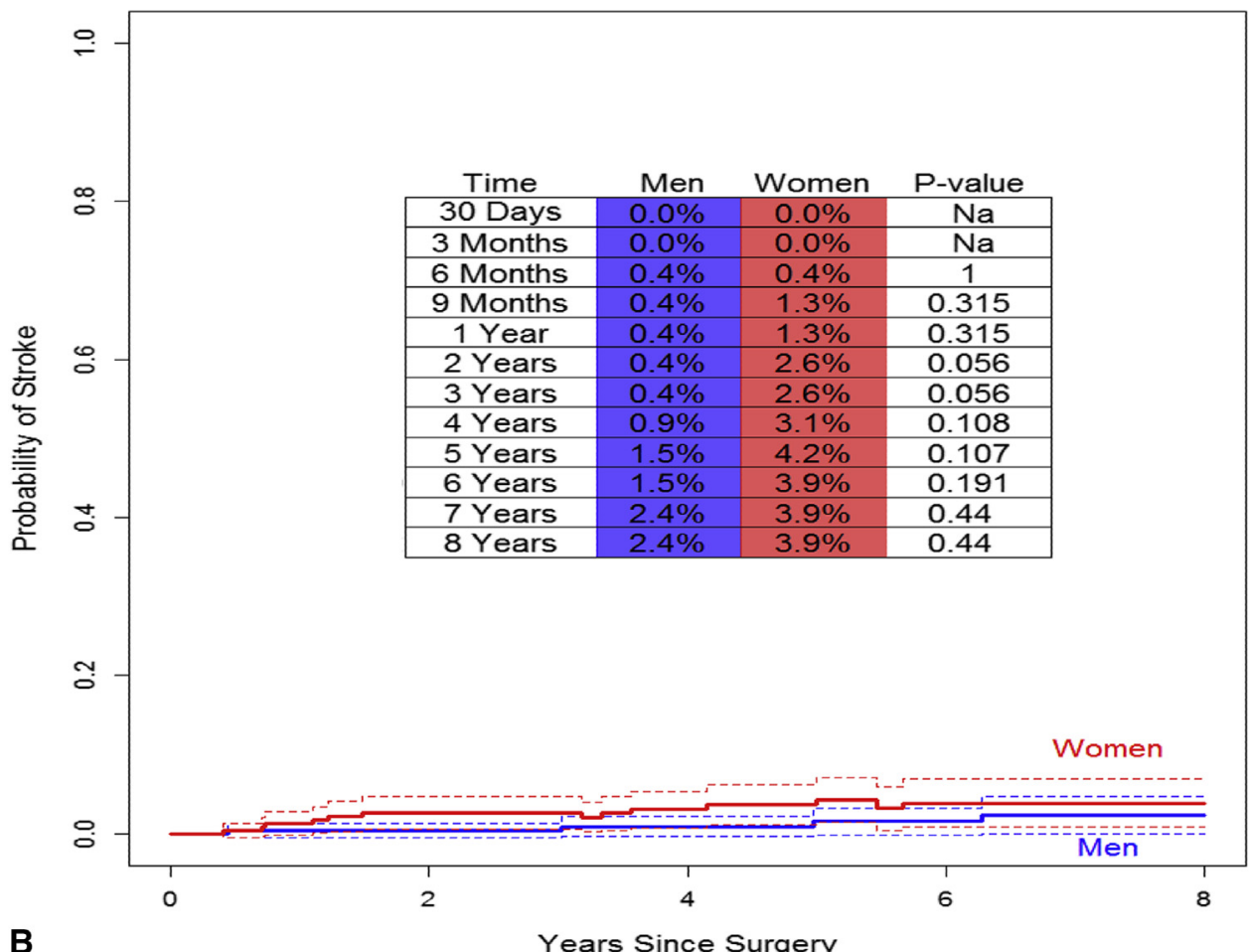

FIGURE 3. Probability of stroke during follow-up in (A) the original groups and (B) the propensity score-matched groups. 
operations with biatrial AF ablation. The other study ${ }^{22}$ included more standalone procedures: 131 of $540(24 \%)$, which were performed in men significantly more often than in women ( $31 \%$ vs $10.5 \%$, respectively; $P<.001)$. We performed isolated AF procedures in only $11 \%$ of cases, with more of them being for men before, but not after, propensity-score matching $(10 \%$ vs $10 \% ; P=.88)$. The groups of women and of men both underwent various lesion sets depending on the concomitant surgery.

We have never endorsed the strategy of using the full Cox maze procedure for all types of $\mathrm{AF}$ in all procedures (eg, 1 or 2 episodes of paroxysmal AF before aortic valve replacement or coronary artery bypass; 10 years of persistent AF before mitral valve surgery). We have performed some type of AF ablation on a large majority of patients undergoing various procedures, in many cases a reoperation $(18 \%)$. Therefore, our patient population includes more than one type of ablation approach. However, gender was not a consideration when the procedure was chosen, as reflected in Table 2. In addition, results of a recent randomized trial raise the question of whether a full lesion set is needed in all patients. ${ }^{25}$

Our study is the first to describe gender differences in surgical ablation of AF in propensity score-matched groups. In unadjusted analyses, we found gender disparities in cardioversion and catheter ablation rates after $\mathrm{AF}$ recurrence, with men being more likely than women to undergo subsequent treatment. We additionally found that the postsurgical stroke rate per 10 person-years was higher for women, compared with that for men. However, after propensity-score matching, these differences were no longer significant, nor were gender differences in cardioversion or catheter ablation after AF recurrence, after adjustment for age alone. These results suggest that a patient's decision or a physician's referral to undergo more invasive procedures after surgical ablation may depend on age alone, and not on patient gender.

Atrial fibrillation is associated with a higher risk of stroke in women as they age, compared with men, and is an important long-term consideration in all AF patients regardless of gender. ${ }^{21}$ In our study, stroke rate trended slightly higher in women before propensity-score matching. The CHADS2 scores were similar in men and women before propensityscore matching took place, suggesting that female gender by itself, a known risk factor for stroke, may have accounted for this trend toward a slight increase in stroke rates in women compared with men.

Tsadok and colleagues ${ }^{8}$ found that among patients $>65$ years old diagnosed with AF, the unadjusted overall incidence of stroke per 100 person-years was higher in women than in men $(2.02$ vs $1.61 ; P<.001)$. After covariate adjustments, the risk of stroke remained higher in women $(1.14[1.07,1.22]) .{ }^{21}$ However, no covariate-adjusted analyses for the incidence of stroke are presented. Unlike results reported in the medical literature, we found no difference in stroke rate or CHADS2 scores, but a lower overall stroke rate than was previously reported $(0.15$ per 10 person-years in women, vs 0.20 per 10 person-years in the study by Tsadok and colleagues ${ }^{8}$ ).

Our study indicated, in adjusted analyses, a slight trend toward men being more likely than women to be discharged while taking a statin. Although studies on the general population suggest that lifestyle risk factors may account for the bulk of instances contributing to this finding, data on postoperative statin use, specifically after surgical AF ablation, are limited. ${ }^{26}$ However, preoperative statin administration has been associated with early reductions in mortality among patients undergoing isolated valvular heart surgery, and with better long-term overall survival. ${ }^{27}$ In addition, numerous studies have indicated that statin therapy is associated with a significantly decreased risk of mortality in both women and men and should thus be used in appropriate patients without consideration as to gender. ${ }^{28}$

This study has important clinical implications and adds to the limited data regarding AF surgery outcomes by gender. Women with AF are consistently shown to have a higher symptom burden, higher stroke risk, and higher mortality, compared with men. Additionally, women experience more side effects from AADs. ${ }^{2-4}$ In our study, women and men were found to have similar long-term outcomes after surgical ablation for AF, in terms of both overall survival and freedom from $\mathrm{AF}$ without AADs at last follow-up. Results of AF surgery did not differ by gender among the 4 lesion sets used. Given these findings, curative surgical ablation of AF is an attractive option and should be considered in qualifying patients, regardless of their gender.

This study has several limitations. First, it is a singlecenter, observational study, so the present findings may not be generalizable to other centers. Second, several lesion sets have been applied in the AF ablation procedures by 5 surgeons, some of whom use ablation more conservatively than others. Our sample size was relatively small after propensity-score matching. Finally, ablation was not performed on patients who had AF but for whom the risk of the procedure was deemed to be too high; thus, the full range of the population of patients with $\mathrm{AF}$ who undergo cardiac surgery was not represented in our study.

In conclusion, women who undergo surgical ablation for $\mathrm{AF}$ are older and sicker preoperatively, and they have similarly favorable overall survival and freedom from AF outcomes, compared with men. Further, late cardioversion or catheter ablation patterns did not differ by gender. Given these findings, a curative surgical ablation of AF should be considered in qualifying patients, regardless of gender.

\section{Conflict of Interest Statement}

Dr Passman reports fees from Boehringer Ingelheim, Pfizer, and Bristol Myers Squibb, and fees and grant supoport from 
Medtronic. All other authors have nothing to disclose with regard to commercial support.

\section{References}

1. Kannel WB, Abbott RD, Savage DD, McNamara PM. Epidemiologic features of chronic atrial fibrillation: the Framingham study. N Engl J Med. 1982;306: 1018-22.

2. Humphries KH, Kerr CR, Connolly SJ, Klein G, Boone JA, Green M, et al New-onset atrial fibrillation: sex differences in presentation, treatment, and outcome. Circulation. 2001;103:2365-70.

3. Dagres N, Clague JR, Breithardt G, Borggrefe M. Significant gender-related differences in radiofrequency catheter ablation therapy. J Am Coll Cardiol. 2003;42:1103-7.

4. Bernal O, Moro C. Cardiac arrhythmias in women. Rev Esp Cardiol. 2006;59 609-18

5. Volgman AS, Manankil MF, Mookherjee D, Trohman RG. Women with atrial fibrillation: greater risk, less attention. Gend Med. 2009;6:419-32.

6. Paquette M, Roy D, Talajic M, Newman D, Couturier A, Yang C, et al. Role of gender and personality on quality-of-life impairment in intermittent atrial fibrillation. Am J Cardiol. 2000;86:764-8.

7. Friberg J, Scharling H, Gadsbøll N, Truelsen T, Jensen GB, Copenhagen City Heart Study. Comparison of the impact of atrial fibrillation on the risk of stroke and cardiovascular death in women versus men (The Copenhagen City Heart Study). Am J Cardiol. 2004;94:889-94.

8. Tsadok MA, Jackevicius CA, Rahme E, Humphries KH, Behlouli H, Pilote L. Sex differences in stroke risk among older patients with recently diagnosed atrial fibrillation. JAMA. 2012;307:1952-8.

9. Forleo GB, Tondo C, De Luca L, Dello Russo A, Casella M, De Sanctis V, et al. Gender-related differences in catheter ablation of atrial fibrillation. Europace. 2007;9:613-20.

10. Dagres N, Nieuwlaat R, Vardas PE, Andresen D, Levy S, Cobbe S, et al Gender-related differences in presentation, treatment, and outcome of patients with atrial fibrillation in Europe: a report from the Euro Heart Survey on Atrial Fibrillation. J Am Coll Cardiol. 2007;49:572-7.

11. Winkle RA, Mead RH, Engel G, Patrawala RA. Long-term results of atrial fibrillation ablation: the importance of all initial ablation failures undergoing a repeat ablation. Am Heart J. 2011;162:193-200.

12. Heist EK, Chalhoub F, Barrett C, Danik S, Ruskin JN, Mansour M. Predictors of atrial fibrillation termination and clinical success of catheter ablation of persistent atrial fibrillation. Am J Cardiol. 2012;110:545-51.

13. Patel D, Mohanty P, Di Biase L, Sanchez JE, Shaheen MH, Burkhardt JD, et al Outcomes and complications of catheter ablation for atrial fibrillation in females. Heart Rhythm. 2010;7:167-72.

14. Gammie JS, Haddad M, Milford-Beland S, Welke KF, Ferguson TB, O’Brein SM, et al. Atrial fibrillation correction surgery: lessons from the Society of Thoracic Surgeons National Cardiac Database. Ann Thorac Surg. 2008;85:909-14.
15. Damiano RJ Jr, Gaynor SL, Bailey M, Prasad S, Cox JL, Boineau JP, et al. The long-term outcome of patients with coronary disease and atrial fibrillation undergoing the Cox maze procedure. J Thorac Cardiovasc Surg. 2003;126: 2016-21.

16. Stulak JM, Sundt TM III, Dearani JA, Daly RC, Orsulak TA, Schaff HV. Ten-year experience with the Cox-maze procedure for atrial fibrillation: How do we define success? Ann Thorac Surg. 2007;83:1319-24.

17. McCarthy PM, Kruse J, Shalli S, Ilkhanoff L, Goldberger JJ, Kadish AH, et al. Where does atrial fibrillation surgery fail? Implications for increasing effectiveness of ablation. J Thorac Cardiovasc Surg. 2010;139:860-7.

18. Lee R, Kruse J, McCarthy PM. Surgery for atrial fibrillation. Nat Rev Cardiol. 2009;6:505-13

19. Lee R, McCarthy PM, Wang EC, Vaduganathan M, Kruse J, Malaisrie SC, et al Midterm survival in patients treated for atrial fibrillation: a propensity-matched comparison to patients without a history of atrial fibrillation. J Thorac Cardiovasc Surg. 2012;143:1341-51

20. Cox JL, Ad N, Palazzo T. Impact of the maze procedure on the stroke rate in patients with atrial fibrillation. J Thorac Cardiovasc Surg. 1999;118 $833-40$

21. Calkins H, Kuck KH, Cappato R, Brugada J, Camm AJ, Chen SA, et al. 2012 HRS/EHRA/ECAS Expert Consensus Statement on Catheter and Surgical Ablation of Atrial Fibrillation: recommendations for patient selection, procedural techniques, patient management and follow-up, definitions, endpoints, and research trial design. Europace. 2012;14:528-606.

22. Henry L, Hunt S, Holmes SD, Martin LM, Ad N. Are there gender differences in outcomes after the Cox-Maze procedure for atrial fibrillation? Innovations. 2013; 8:190-8.

23. Rosner B. Fundamentals of Biostatistics. Boston, Mass: Cengage Learning; 2010

24. Andersen PK, Borgan O, Gill RD, Keiding N. Statistical Models Based on Counting Processes. New York: Springer-Verlag; 1993.

25. Gillinov AM, Gelijns AC, Parides MK, DeRose JJ, Moskowitz AJ, Voisine P, et al. Surgical ablation of atrial fibrillation during mitral-valve surgery. $N$ Engl J Med. 2015;372:1399-409.

26. Bhattacharjee S, Findley PA, Sambamoorthi U. Understanding gender differences in statin use among elderly Medicare beneficiaries: an application of decomposition technique. Drugs Aging. 2012;29:971-80.

27. Vaduganathan M, Stone NJ, Andrei AC, Lee R, Kansal P, Silverberg RA, et al. Midterm benefits of preoperative statin therapy in patients undergoing isolated valve surgery. Ann Thorac Surg. 2012;93:1881-7.

28. Kostis WJ, Cheng JQ, Dobrzynski JM, Cabrera J, Kostis JB. Metaanalysis of statin effects in women versus men. J Am Coll Cardiol. 2012;59: $572-82$

Key Words: atrial fibrillation, outcomes, quality care management 


\section{Original Groups}

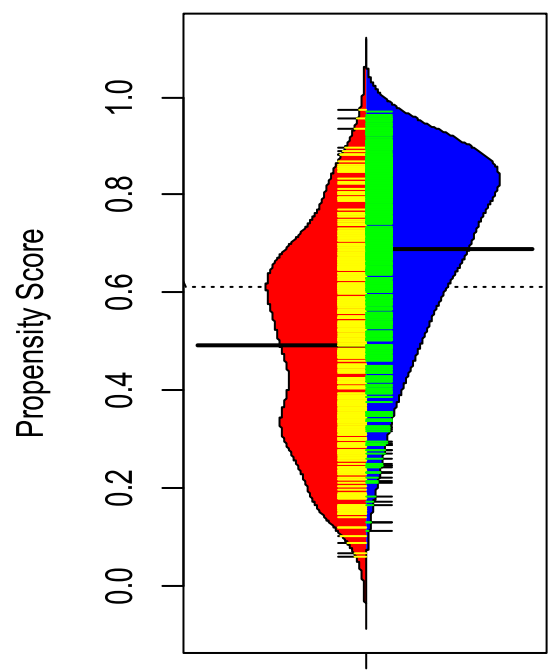

Female+Male

\section{PS-Matched Groups}

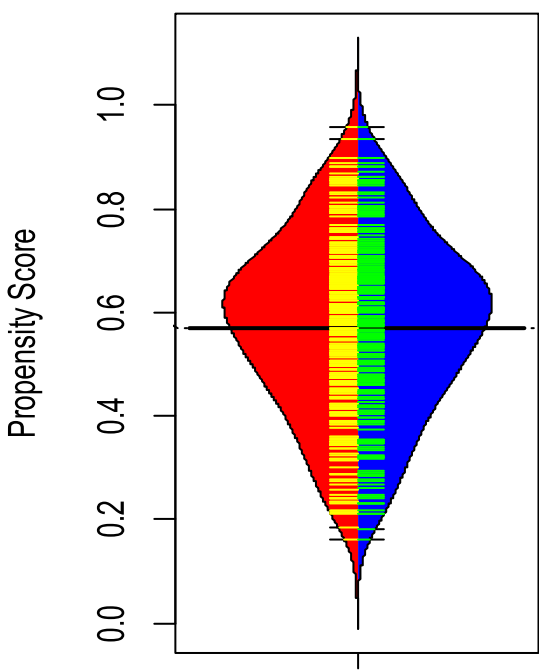

Female+Male

FIGURE E1. Kernel-smoothed histograms of the PS, before and after PS-matching, are shown below; they indicate excellent PS similarity by gender after PS-matching. Red and blue are associated with female and male gender, respectively. Values of the propensity scores are shown in yellow (for women) and green (for men). PS, Propensity score. 
TABLE E1. Summary of the logistic regression model of the probability of being male

\begin{tabular}{|c|c|c|c|c|}
\hline Parameter & Estimate & SE & Wald $\chi^{2}$ & $\begin{array}{c}P \\
\text { Value }\end{array}$ \\
\hline Intercept & 4.1123 & 0.9064 & 20.5835 & $<.0001$ \\
\hline Age & -0.0306 & 0.00809 & 14.2676 & .0002 \\
\hline Body mass index & -0.00229 & 0.0140 & 0.0265 & .8707 \\
\hline $\begin{array}{l}\text { Left ventricular ejection } \\
\text { fraction }\end{array}$ & -0.0309 & 0.00705 & 19.1751 & $<.0001$ \\
\hline $\begin{array}{l}\text { Coronary artery disease, } \\
\text { missing }\end{array}$ & 0.1768 & 0.2986 & 0.3508 & .5537 \\
\hline Coronary artery disease, yes & -0.4772 & 0.1684 & 8.0276 & .0046 \\
\hline $\begin{array}{l}\text { Family history of coronary } \\
\text { artery disease }\end{array}$ & 0.1860 & 0.1079 & 2.9708 & .0848 \\
\hline Mitral valve surgery & 0.3224 & 0.0914 & 12.4422 & .0004 \\
\hline Tricuspid valve surgery & 0.3933 & 0.0924 & 18.1324 & $<.0001$ \\
\hline Aortic valve surgery & -0.1232 & 0.0916 & 1.8075 & .1788 \\
\hline Diabetes & 0.1127 & 0.1083 & 1.0821 & .2982 \\
\hline Hypercholesterolemia & -0.1645 & 0.0949 & 3.0037 & .0831 \\
\hline Hypertension & -0.0923 & 0.0888 & 1.0797 & .2988 \\
\hline Prior myocardial infarction & 0.0683 & 0.1370 & 0.2485 & .6181 \\
\hline Chronic lung disease & 0.1528 & 0.1075 & 2.0183 & .1554 \\
\hline $\begin{array}{l}\text { Prior coronary artery bypass } \\
\text { grafting }\end{array}$ & -0.6116 & 0.2294 & 7.1080 & .0077 \\
\hline Prior congestive heart failure & -0.0429 & 0.0908 & 0.2229 & .6368 \\
\hline Prior valve procedure & 0.0171 & 0.2052 & 0.0070 & .9334 \\
\hline $\begin{array}{l}\text { Prior cardiovascular } \\
\text { intervention }\end{array}$ & 0.0706 & 0.0947 & 0.5560 & .4559 \\
\hline NYHA functional class III-IV & 0.3407 & 0.0904 & 14.2121 & .0002 \\
\hline Elective surgery & -0.1517 & 0.1278 & 1.4084 & .2353 \\
\hline Repeat sternotomy & 0.0744 & 0.2070 & 0.1290 & .7194 \\
\hline $\begin{array}{l}\text { Preoperative lipid-lowering } \\
\text { medication }\end{array}$ & -0.1664 & 0.0948 & 3.0824 & .0791 \\
\hline $\begin{array}{l}\text { Preoperative antiarrhythmia } \\
\text { medication }\end{array}$ & 0.2434 & 0.0943 & 6.6547 & .0099 \\
\hline
\end{tabular}

For all parameters, degrees of freedom $=1$. The area under the receiver operating characteristic curve $=0.763$. To ensure adequate model calibration, we used the Hosmer and Lemeshow goodness-of-fit test: the test statistic $=4.87$, with $8^{\circ}$ degrees of freedom, and $P$ value $=.77$, indicating good model calibration. $S E$, Standard error; NYHA, New York Heart Association. 